\title{
17ß-estradiol-induced mitochondrial dysfunction and Warburg effect in cervical cancer cells allow cell survival under metabolic stress
}

\author{
ANNIE RIERA LEAL ${ }^{1 *}$, PABLO CÉSAR ORTIZ-LAZARENO ${ }^{2 *}$, LUIS FELIPE JAVE-SUÁREZ ${ }^{2}$, \\ ADRIÁN RAMÍREZ DE ARELLANO ${ }^{3}$, ADRIANA AGUILAR-LEMARROY ${ }^{2}$, YVETH MARLENE ORTIZ-GARCÍA ${ }^{1}$, \\ CARLOS ALFREDO BARRÓN-GALLARDO ${ }^{2}$, RAÚL SOLÍS-MARTÍNEZ ${ }^{4}$, SONIA LUQUIN DE ANDA ${ }^{5}$, \\ JOSÉ FRANCISCO MUÑOZ-VALLE ${ }^{3}$ and ANA LAURA PEREIRA-SUÁREZ ${ }^{2,3}$

\footnotetext{
${ }^{1}$ Laboratory of Immunology, Department of Physiology, University Center for Health Sciences, University of Guadalajara;

${ }^{2}$ Division of Immunology, Western Biomedical Research Center, Mexican Social Security Institute;

${ }^{3}$ Research Institute in Biomedical Sciences; ${ }^{4}$ Diagnostic Laboratory and ${ }^{5}$ Department of Neurosciences,

University Center for Health Sciences, University of Guadalajara, Guadalajara, Jalisco 44340, Mexico
}

Received April 4, 2019; Accepted August 19, 2019

DOI: $10.3892 /$ ijo.2019.4912

\begin{abstract}
Mitochondria from different types of cancer show bioenergetics and dysfunction that favor cell proliferation. The mechanistic understanding of estrogen in cervical cancer is poorly understood. Therefore, the objective of this study was to determine how $17 \beta$-estradiol (E2) affects mitochondrial function and the Warburg effect in SiHa, HeLa and C33A cervical cancer cells. Mitochondrial compromise was evaluated measuring changes in the membrane permeability by immunofluorescence, calcium concentration, redox status, iron and ferritin reserves. Glucose consumption and lactic acid assays were used to detect the metabolic activity. Results were confirmed at molecular level by analysis of the differential gene expression using RNA sequencing. E2 modified the mitochondrial permeability and produced an alteration in the calcium signaling pathway. In HeLa and $\mathrm{SiHa}$, there was a significant decrease in nitric oxide levels and lipid peroxidation, and an increase in glucose consumption and lactic acid levels when stimulated with E2. Intracellular iron or ferritin reserves were not affected by the E2 treatment. Genes differentially modulated by E2 were involved in the mitochondrial electron transport chain, oxidative phosphorylation system, glycolysis, pentose phosphate pathway and the regulation of
\end{abstract}

Correspondence to: Dr Ana Laura Pereira-Suárez, Laboratory of Immunology, Department of Physiology, University Center for Health Sciences, University of Guadalajara, 950 Sierra Mojada, Colonia Independencia, Guadalajara, Jalisco 44340, Mexico

E-mail: analauraps@hotmail.com

${ }^{*}$ Contributed equally

Key words: mitochondrial function, antioxidant, Warburg effect, estradiol metabolic signaling pathways. Herein, we provide evidence for a primary effect of estrogen on mitochondrial function and the Warburg effect, favoring the metabolic adaptation of the cervical cancer cell lines and their survival.

\section{Introduction}

Cervical cancer is one of the most prevalent cancer worldwide with an incidence of 500,000 new cases and mortality of 270,000 women recorded in 2018 (1). Patients with high levels of estrogen and the estrogen receptor alpha $(\mathrm{ER} \alpha)$ are at increased risk of developing this type of tumor (2). Recently, our group described the tumor-promoting effect of $17 \beta$-estradiol (E2) through the induction of changes in cervical cancer cells metabolism (3). It remains to define how E2 produces these modifications.

Metabolism is one of the most complex processes in biological systems. The effect of the metabolism in cancer cells was first described by Otto Warburg in 1924 (4). Several hypotheses have been proposed to explain how tumor cells activate glycolysis under aerobic conditions. Asgari et al (5) described seven subsystems that form the basis of the Warburg effect, including glutamine metabolism, nucleotides, glycolysis, oxidative phosphorylation system (OXPHOS), pentose phosphate pathway, tricarboxylic acid (TCA) cycle and pyruvate metabolism. Even though Warburg postulated impaired mitochondrial respiration in tumor cells (4), the role of mitochondria in the malignant transformation is still not well understood.

Mitochondria are organelles with vital roles in cellular energy production. Functionally, they are best known for their ability to generate the majority of ATP and free radicals from NADH and FADH using molecular oxygen $\left(\mathrm{O}_{2}\right)$ via electron transfer coupled with the OXPHOS (5). Also, they are involved in the modulation of various cellular processes, such as the intracellular calcium homeostasis, fatty acid oxidation, urea cycle, biosynthesis of amino acids, lipids, hemes and purines, and other central metabolic pathways. A close link 
between attenuated mitochondrial bioenergetics and enhanced glycolysis dependency is present in human tumor cells (6).

Estrogen has been shown to influence mitochondrial structure, biogenesis and activity (7). The majority of the biological effects of E2 are mediated via two ERs, namely ER $\alpha$ and ER $\beta$. Both ERs are localized in the mitochondria and they play an important role in the regulation of the organelle structure and function $(7,8)$.

Under various stress conditions, the major function of E2 is to maintain OXPHOS in mitochondria, explaining the neuroprotective and cardioprotective effects of estrogens $(9,10)$. The stressed mitochondria produce excessive amounts of reactive oxygen species (ROS), which can damage in the lipid bilayers, mutate DNA and alter the activity of specific enzymes critical for the maintenance of oxidative function (11). Estrogens act as free-radical scavengers, and modify the cytosolic and mitochondrial influx of calcium ions $\left(\mathrm{Ca}^{2+}\right)$ potentially providing protection to the cell from toxic $\mathrm{Ca}^{2+}$ influx (12). Collectively, these effects indicate that the hormone protects from mitochondrial membrane potential collapse, avoids the loss of the inner mitochondrial membrane integrity and inhibits the release of pro-apoptotic factors.

In tumor cells, there is a change in the metabolic profile to support proliferation and the increased biosynthetic demands. These cells have an alteration of the mitochondrial activity and a high rate of glycolysis, followed by increased lactic acid production under aerobic conditions (13). In this work, we tested the association between the activity of E2 and its ability to moderate the Warburg effect and the mitochondrial function in cell lines derived from cervical cancer with the aim to define the role of this hormone in the process of cervical carcinogenesis.

\section{Materials and methods}

Reagents. E2, phorbol myristate acetate (PMA; cat. no. PI585-1 mg), ionomycin calcium salt (cat. no. IO634), cisplatin (cat. no. 479306), sulfuric acid (cat. no. 7664-93-9), phosphotungstic acid hydrate (cat. no. 12501-23-4), 2-thiobarbituric acid (TBA; cat. no. 504-17-6) and metformin were purchased from Calbiochem (cat. no. D150959; Merck KGaA). 1-[4-(6-bromobenzo[1,3](8)dioxol-5yl)-3a,4,5,9btetrahydro-3H-cyclopenta[c]quinolin-8-yl]-ethanone (G-1; cat. no. 10008933) was obtained from Cayman Chemical Company. DMEM, charcoal stripped fetal bovine serum (FBS) and antibiotics were purchased from Gibco (Thermo Fisher Scientific, Inc.). mitoCapture ${ }^{\mathrm{TM}}$ (cat. no. K250) was acquired through BioVision, Inc., and 1-butanol and Baker Analyzed ${ }^{\mathrm{TM}}$ A.C.S. were from Avantor, Inc.

Cell lines. Cervical carcinoma cell lines were obtained from the American Type Culture Collection, including HeLa [positive to human papillomavirus (HPV) 18], SiHa (positive to HPV 16) and C33A (negative to HPV). Non-tumorigenic HaCaT was cultured as mock control; cells maintained normal properties of differentiation and were kindly provided by Dr. Petra Boukamp (German Cancer Research Center; DKFZ). Cell lines were tested and authenticated by the Multiplexion's Multiplex Cell Line Authentication tests in September 2018 (www.multiplexion.de).
Cell culture. Cells were cultured in DMEM containing 1\% antibiotic [penicillin $\mathrm{G}(10,000 \mathrm{U} / \mathrm{ml})$ and streptomycin $(10,000 \mu \mathrm{g} / \mathrm{ml})]$, amphotericin B $(250 \mu \mathrm{g} / \mathrm{ml})$ and $10 \%$ of charcoal-stripped $\mathrm{FBS}$ at $37^{\circ} \mathrm{C}$ in a humidified atmosphere with $5 \% \mathrm{CO}_{2}$. Cells were grown until reaching 70-80\% confluence. Three to four passages were achieved before the experiments were performed.

Mitochondrial permeability. Cell lines were cultured on 8-well slides (cat. no. 177402; Sigma-Aldrich; Merck KGaA) at $5 \times 10^{3} /$ well for HeLa and $\mathrm{SiHa}$ or at $10 \times 10^{3} /$ well for C33A and HaCaT. Cells were stimulated with E2 (10 nM), as previously determined (3) and incubated for $24 \mathrm{~h}$. Staining was performed using the MitoCapture ${ }^{\mathrm{TM}}$ staining according to the manufacturer's instructions and examined under a fluorescence microscope coupled to a digital camera (magnification, x10 and $\mathrm{x} 40$ ). In healthy cells, dye aggregates and stains the mitochondria red; in abnormal cells, the mitochondrial membrane potential collapses and the dye remains in the cytoplasm in its green fluorescent monomeric form. As in recent years evidence suggested that low concentrations of chemotherapeutic agents, like cisplatin, facilitate malignancy of carcinoma cells $(14,15)$, cisplatin $(0.5 \mu \mathrm{g} / \mathrm{ml})$ was used as control of cellular and mitochondrial damages and were compared with a basal control (no treatment). The evaluation of the mean optical density was determined using Image-pro Plus 6.0 (Media Cybernetics, Inc.) based on the red staining; data were normalized to the fluorescence of vehicle-treated cells. Each sample was tested by triplicate in three independent experiments.

Calcium pathway. The effect of E2 (10 nM) on intracellular $\mathrm{Ca}^{2+}$ concentration was measured using the Fluo-4 Calcium kit (cat. no. F36206; Molecular Probes; Thermo Fisher Scientific, Inc.) according to the manufacturer's instructions. The supernatant of the cells was obtained $48 \mathrm{~h}$ after applying E2. Ionomycin (750 ng/ml) and PMA (10 ng/ml) stimuli were applied for $5 \mathrm{~min}$ at $37^{\circ} \mathrm{C}$ before the analysis of the samples in the spectrophotometer. Excitation and emission wavelengths were 494 and $516 \mathrm{~nm}$, respectively. Readings were recorded every minute over $16 \mathrm{~min}$. G1 $(1 \mu \mathrm{M})$ was used as a positive control alone or in combination with PMA $(10 \mathrm{ng} / \mathrm{ml})$ and ionomycin (750 ng/ml) and were compared with a basal control.

Nitric oxide $(N O)$ concentration. Cells $\left(5 \times 10^{3}\right)$ were seeded in 96-well plates with DMEM containing $10 \%$ charcoal-stripped FBS. Cells were stimulated with E2 (10 nM) and/or metformin $(10 \mathrm{mM})$ and were compared with a basal control. After $48 \mathrm{~h}$, nitrite concentrations were measured using the Measure-i $\mathrm{T}^{\mathrm{TM}}$ High-Sensitivity Nitrite assay (Invitrogen; Thermo Fisher Scientific, Inc.). The amount of nitrite is extrapolated to NO concentrations following the manufacturer's instructions. Reagent (Measure-iT ${ }^{\mathrm{Tм}}$ nitrite quantitation reagent; $2.0 \mathrm{ml}$ of $100 \mathrm{X}$ in $0.62 \mathrm{M} \mathrm{HCl} ; 1: 100 ; 100 \mu \mathrm{l}$ ) was added to the wells and samples $(10 \mu \mathrm{l})$ were added. After $10 \mathrm{~min}$ at room temperature, $5 \mu \mathrm{l}$ developer solution was added and the fluorescence was measured using a spectrophotometer (excitation and emission wavelength, 360 and $460 \mathrm{~nm}$, respectively).

Lipid peroxidation. The levels of lipid peroxides were calculated via determining the malondialdehyde (MDA) 
concentrations. Cells were stimulated with E2 (10 nM) and/or metformin $(10 \mathrm{mM})$ and were compared with a basal control. After $48 \mathrm{~h}, 300 \mu \mathrm{l}$ cell supernatant was mixed with $2 \mathrm{ml}$ sulfuric acid (N/12), $0.3 \mathrm{ml} \mathrm{10 \%} \mathrm{phosphotungstic} \mathrm{acid} \mathrm{and} 1 \mathrm{ml} 0.6 \%$ TBA. The mixture was placed in a boiling water bath at $95^{\circ} \mathrm{C}$ for $1 \mathrm{~h}$, followed by cooling at room temperature. Then, $1.3 \mathrm{ml}$ of n-butane was added, mixed vigorously and centrifuged at $1,400 \mathrm{x} g$ for $15 \mathrm{~min}$. The absorption of the organic phase was recorded at $534 \mathrm{~nm}$.

Concentration of iron and ferritin. Cell supernatants were used to determine iron concentrations and to evaluated ferritin levels. Cells were stimulated with E2 $(10 \mathrm{nM})$ and incubated for $48 \mathrm{~h}$ and were compared with a basal control. The VITROS Fe slide method was performed using the VITROS Fe slides and the VITROS Calibrator 4 kit (Thermo Fisher Scientific, Inc.) according to the manufacturer's instructions. The difference in the density of the reflectance after $1-5 \mathrm{~min}$ is proportional to the concentration of iron in the samples. The determination of the ferritin levels was determined using the same samples with the IMMULITE ${ }^{\circledR}$ kit (cat. no. L2KFE2; Siemens Healthineers) following the manufacturer's instructions.

Concentration of glucose. Cells were stimulated with E2 (10 $\mathrm{nM})$ and/or metformin $(10 \mathrm{mM})$ and were compared with a basal control. The supernatant was obtained after 48 h. Glucose concentrations were measured in the BS-120 Clinical Chemistry analyzer (Shenzhen Mindray Bio-Medical Electronics Co., Ltd.) using the glucose oxidase method (COD11803; BioSystems S.A.) following the manufacturer's instructions. Glucose in the samples generated a colored complex that was quantified spectrophotometrically at $500 \mathrm{~nm}$.

Concentration of lactic acid. Cells were stimulated with E2 $(10 \mathrm{nM})$ and/or metformin $(10 \mathrm{mM})$ and were compared with a basal control. The supernatant was obtained after $48 \mathrm{~h}$. The VITROS LAC Slide method was performed using the VITROS LAC slides and the VITROS Calibrator kit 1 (Thermo Fisher Scientific, Inc.) according to the manufacturer's instructions. Lactate in samples is oxidized to pyruvate and hydrogen peroxide $\left(\mathrm{H}_{2} \mathrm{O}_{2}\right)$. The generated $\mathrm{H}_{2} \mathrm{O}_{2}$ oxidizes 4-aminoantipyrine, which forms a complex with 1,7-dihydroxynaphthalene. Absorbance at $540 \mathrm{~nm}$ was determined spectrophotometrically.

RNA extraction. Cells were stimulated with E2 (10 nM) and incubated for $48 \mathrm{~h}$ and were compared with a basal control. Total RNA was extracted from $\mathrm{SiHa}$ and HeLa using the RNeasy Plus Mini kit (cat. no. 74136; Qiagen, Inc.), according to the manufacturer's instructions. RNA was quantified measuring the absorbance at 260/280 $\mathrm{nm}$.

RNA sequencing. Transcriptome sequencing was performed using RNAseq technology. The samples ( $\mathrm{SiHa}$ and HeLa cells) stimulated with E2 were sent to the Genome Institute (Novogene Corporation, Inc.), where the Illumina HiSeq 4000 system was used; the sequencing strategy included a 250-300 bp insert cDNA library, HiSeq platform, paired-end 150 and 50 bp single-end. The RNA quality was measured and selection criteria were: Amount $\geq 1 \mu \mathrm{g}$; volume $\geq 20 \mu \mathrm{l}$; concentration $\geq 50 \mathrm{ng} / \mu \mathrm{l}$; RNA integrity number value $\geq 7 ; 28 \mathrm{~S} / 18 \mathrm{~S}$
$>1$; no degradation or pollution. Subsequently, fragmentation of mRNA and synthesis of cDNA of the first and second chain was performed. For the mRNA isolation and fragmentation, $200 \mathrm{ng}$ total RNA was purified using oligo-dT beads and poly (A)-containing mRNA were fragmented into small pieces with Fragment Buffer. For the cDNA synthesis, first-strand cDNA was generated using the First Strand Master Mix and Super Script II (Invitrogen; Thermo Fisher Scientific, Inc.) for $25^{\circ} \mathrm{C}$ for $10 \mathrm{~min}, 42^{\circ} \mathrm{C}$ for $50 \mathrm{~min}$ and $70^{\circ} \mathrm{C}$ for $15 \mathrm{~min}$. Then Second Strand Master Mix was added to synthesize the second-strand cDNA $\left(16^{\circ} \mathrm{C}\right.$ for $\left.1 \mathrm{~h}\right)$.

cDNA fragments were purified, resolved for the final repair and the adenine single nucleotide addition was performed. cDNA fragments were ligated using adapters and fragments with a suitable size were selected for PCR amplification. The library construct was prepared for the quantification and qualification of libraries. For the end repair, the purified fragmented cDNA was combined with End Repair Mix and incubated at $30^{\circ} \mathrm{C}$ for $30 \mathrm{~min}$. The end-repaired DNA was purified with Ampure XP beads (Thermo Fisher Scientific, Inc.) and incubated with A-Tailing Mix at $37^{\circ} \mathrm{C}$ for $30 \mathrm{~min}$. For the adapter ligation, the adenylated 3 -DNAs were combined and RNA Index Adapter and Ligation Mix was added at $30^{\circ} \mathrm{C}$ for $10 \mathrm{~min}$. The end-repaired DNA was purified with Ampure XP beads. Several rounds of PCR amplification with the PCR Primer Cocktail and PCR Master Mix were performed to enrich the cDNA fragments and products were purified with the Ampure XP beads.

For the validation of the library, quantitation was performed in two ways: (i) Determination of the mean molecule length using the Agilent 2100 bioanalyzer (Agilent Technologies, Inc.); (ii) reverse transcription-quantitative PCR (TaqMan Probe; Illumina, Inc.). Library sequencing was performed as follows: (i) Amplification within the flow cell on the Bot instrument for cluster generation (HiSeq ${ }^{\circledR} 4000$ PE Cluster Kit; Illumina, Inc.); and (ii) loading of the clustered flow cell onto the HiSeq 4000 Sequencer for paired-end sequencing (Illumina; Inc.) with recommended read lengths of $100 \mathrm{bp}$.

Downstream analysis was performed using a combination of programs, including FLEXBAR version 2.5 for filtration (16). Alignments of readings with index hg38 were parsed employing Kallisto version 0.44.0 (17). Differential expression analysis between groups (two biological replicates per group) was performed using the DESeq2 $\mathrm{R}$ package version 1.24.0 (18). The resulting P-values were adjusted applying the Benjamini-Hochberg approach to control the false discovery rate (FDR). Genes with an adjusted $\mathrm{P}<0.05$ were considered as differentially expressed. An absolute fold change of 1 was considered in the significant differential expression. Gene Ontology (19) and KEGG enrichment $(20,21)$ were implemented by the Cluster Profiler R package (https://www.R-project.org). A corrected $\mathrm{P}<0.05$ was considered significantly enriched by differential expressed genes (DEGs).

Cell proliferation assay. Cell proliferation of HeLa, SiHa, $\mathrm{C} 33 \mathrm{~A}$ and HaCaT cells was assessed using the xCELLigence platform (Roche Applied Science). Cells were cultured at $0.25 \times 10^{4} /$ well in 96-well E-plates (cat. no. 058416; ACEA Biosciences, Inc.) and were introduced into the XCELLigence reading station. After $4 \mathrm{~h}$, cells were stimulated with $10 \mathrm{nM}$ E2, 
$10 \mathrm{mM}$ metformin, $1 \mu \mathrm{g} / \mathrm{ml}$ cisplatin alone or in combination (E2+metformin, E2+cisplatin and E2+metformin+cisplatin), a vehicle-stimulated (DMEM+ethanol) cells and were compared with basal control. The proliferation rate was determined in real time every $30 \mathrm{~min}$ over $72 \mathrm{~h}$. Cisplatin stimulation was used as a cell death control. Three independent experiments were performed with three replicates in each case.

Statistical analysis. Statistical analyses were made using SPSS 20 (IBM Corp.) and GraphPad Prism 6 (GraphPad Software, Inc.). Experiments were performed in triplicate and tested in three independent trials. One-way ANOVA with Bonferroni correction was used to determine significance following Levene's test for homogeneity of variances. Data are presented as the mean \pm standard error of the mean. $\mathrm{P}<0.05$ was considered to indicate a statistically significant difference.

\section{Results}

E2 decreases the mitochondrial membrane permeability in cervical cancer cell lines. The effect of E2 on the mitochondrial permeability of cervical cancer and HaCaT cell lines was evaluated using a selective dye. In HeLa, SiHa and C33A, E2 significantly decreased the mitochondrial permeability compared with the basal control ( $\mathrm{P}<0.0001$; Fig. 1). The green color indicated that the dye accumulated in the cytoplasm. In $\mathrm{HaCaT}$ cells, the opposite effect was observed with increased mitochondrial permeability following E2 treatment as suggested by the red color $(\mathrm{P}<0.0001)$.

E2 alters the calcium pathways in SiHa and HeLa. E2 had no significant effect on the calcium concentrations in cervical cancer cells or HaCaT compared with the basal control ( $P>0.05$; Fig. 2). The use of ionomycin plus PMA significantly increased the ion concentration compared with the basal control (HeLa, P=0.003; SiHa, P=0.001; C33A, P=0.001). Exposure to E2, ionomycin and PMA significantly decreased the calcium concentration in SiHa and HeLa compared with the associated control $(\mathrm{P}<0.05)$, suggesting that $\mathrm{E} 2$ altered the calcium signaling pathway. In C33A and $\mathrm{HaCaT}, \mathrm{E} 2 \mathrm{did}$ not significantly modify the cellular response to stimulation with ionomycin plus PMA ( $\mathrm{P}>0.05)$. G1, a selective agonist of the ER in the membrane (GPR30) associated with non-genomic effects, such as calcium mobilization, was used as positive control. E2 and G1 exhibited similar behaviors in all cell lines.

E2 has an antioxidant effect in cervical cancer cell lines. To evaluate the participation of E2 in other mechanisms involved in the mitochondrial activity, we analyzed whether E2 modulated oxidative stress. First, we determined the effect of E2 on the concentration of NO in cervical cancer cells, as well as in HaCaT. E2 significantly decreased NO levels in HeLa, $\mathrm{SiHa}$ and C33A compared with the basal control $(\mathrm{P}=0.0002$, $\mathrm{P}=0.0014$ and $\mathrm{P}=0.0003$; respectively; Fig. 3 ). This effect was significantly reversed when treating cells with metformin and E2 $(\mathrm{P}<0.05)$. In HaCaT cells, no differences were observed following treatment with E2, metformin or a combination of these compared with the control.

Furthermore, we analyzed the concentration of MDA, which is a final product of the lipid peroxidation and is used as a direct indicator of cell damage (22). E2 induced a significant decrease in lipid peroxidation in $\mathrm{HeLa}(\mathrm{P}=0.0004)$ and $\mathrm{SiHa}$ $(\mathrm{P}=0.0005$; Fig. 4) compared with the basal control. In C33A, the effect was the opposite and lipid peroxidation was significantly increased following E2 treatment $(\mathrm{P}=0.0002)$. Treatment with metformin significantly alleviated E2 effects in HeLa and C33A cells $(\mathrm{P}<0.05)$, but no significant effects were observed in $\mathrm{SiHa}(\mathrm{P}>0.05)$. In $\mathrm{HaCaT}$ cells, no significant differences were observed following treatment with E2, metformin or a combination of these compared with the control.

E2 does not modify iron metabolism in cervical cancer cells. The role of iron in lipid peroxidation has been associated with a form of cell death other than apoptosis or necrosis. Ferritin binds to iron and this complex is vital in controlling ROS generation (22). E2 stimulus did not significantly modify intracellular iron or ferritin levels in cervical cancer cells compared with the basal control ( $\mathrm{P}>0.05$; Fig. 5). In HaCaT, intracellular iron was significantly decreased following E2 treatment compared with the basal control $(\mathrm{P}=0.007)$.

E2 favors the Warburg effect. The mitochondrial bioenergetics dysfunction favors the activation of the glycolytic pathway in different types of tumors (13). In HeLa, SiHa and C33A supernatants, there was a significant decrease in glucose levels following $\mathrm{E} 2$ stimulus $(\mathrm{P}=0.0001, \mathrm{P}=0.002$ and $\mathrm{P}=0.0003$; respectively; Fig. 6), suggesting that the cells increased the uptake of glucose. A similar significant decrease was observed using metformin treatment $(\mathrm{P}<0.01)$. The combination of both treatments showed glucose levels similar to those observed in the basal control $(\mathrm{P}>0.05)$. It was hypothesized that the hypoglycemic effect of metformin was associated with E2. Furthermore, E2 significantly increased lactic acid levels in HeLa and SiHa compared with the basal control $(\mathrm{P}=0.0001$ and $\mathrm{P}=0.004$; respectively). The effects were more pronounced with metformin or a combination treatment with E2 $(\mathrm{P}<0.001)$.

E2 modulates DEGs in SiHa and HeLa. Considering that E2 modified the metabolism of the cervical cancer cells, we analyzed the effects of E2 on the expression of molecules associated with metabolic pathways using the RNA sequencing technology. The total number of DEGs in SiHa following E2 treatment was $\sim 3$-fold higher than that in HeLa cells (Fig. 7). E2 stimulus had an impact on various metabolic pathways, including the upregulation of genes involved in the synthesis of proteins associated with the mitochondrial electron transport chain, which may affect OXPHOS and the energy metabolism (Table I). Additionally, upregulation of genes associated with glycolysis was observed (Table I and II), supporting the theory of the role played by E2 in the regulation of the Warburg effect associated with cervical cancer (Fig. 8). Defects in the metabolism of lipids, amino acids, proteoglycans, nucleotides, inositol phosphate, and choline have been reported in different types of cancer (23-25). E2 stimulation modulated various metabolic pathways (Table I). Table II summarized the DEGs shared by HeLa and SiHa.

E2 regulation of the differential expression of transcripts with functional roles in the processes of energy production was demonstrated by evaluating the impact on OXPHOS, glycolysis/gluconeogenesis, lipid processing, vitamins and 


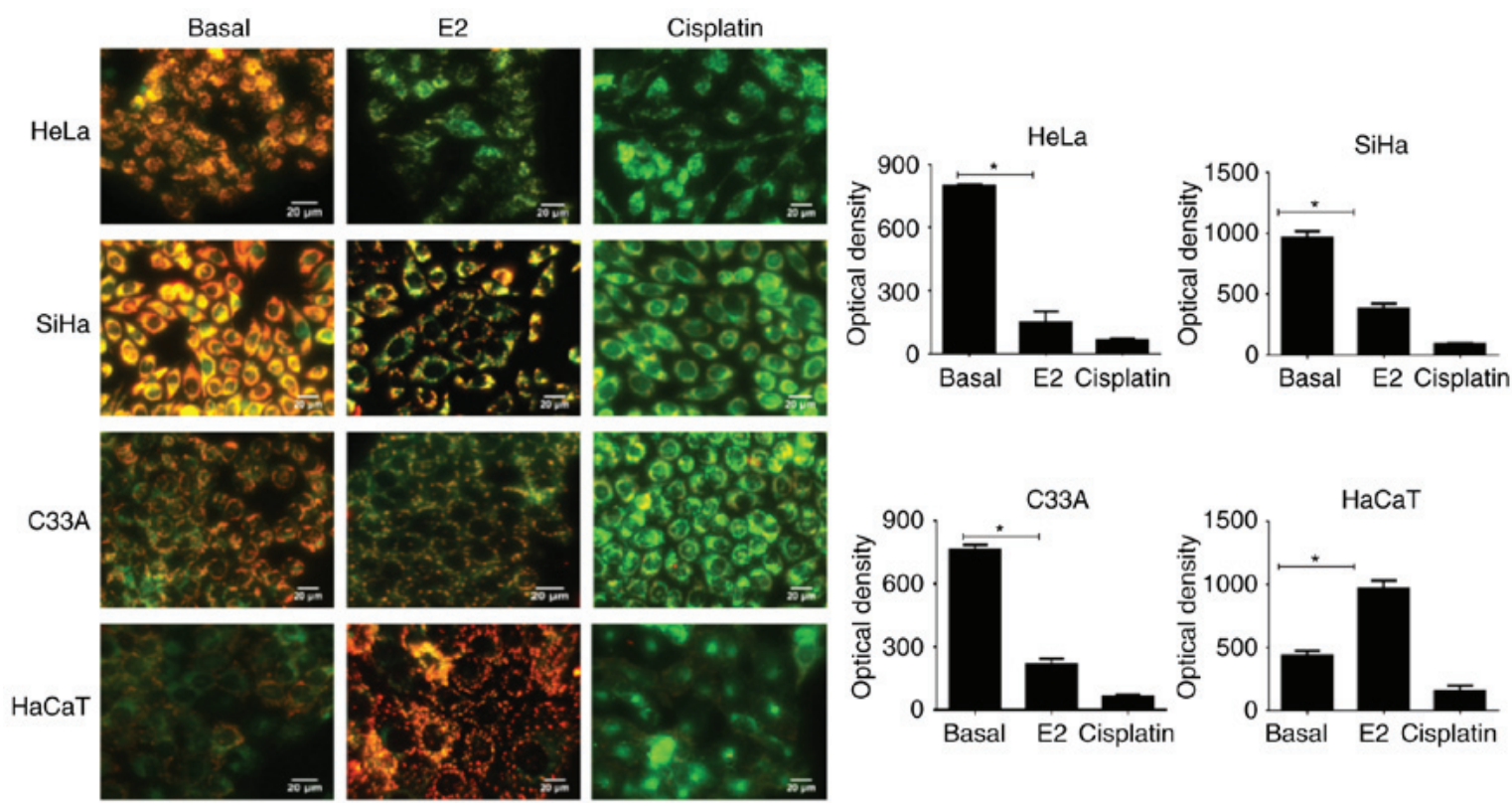

Figure 1. E2 affects mitochondrial permeability of cervical cancer cells. Mitochondrial staining was performed in HeLa, SiHa and C33A cervical cancer cells and $\mathrm{HaCaT}$ following treatment with $\mathrm{E} 2$ or metformin; red, healthy cells and green, abnormal cells; magnification, $\mathrm{x} 40$. The quantification refers to the mean optical density of red stain. Experiments were performed in triplicate and with three repeats. "P $<0.05$. E2, $17 \beta$-estradiol.
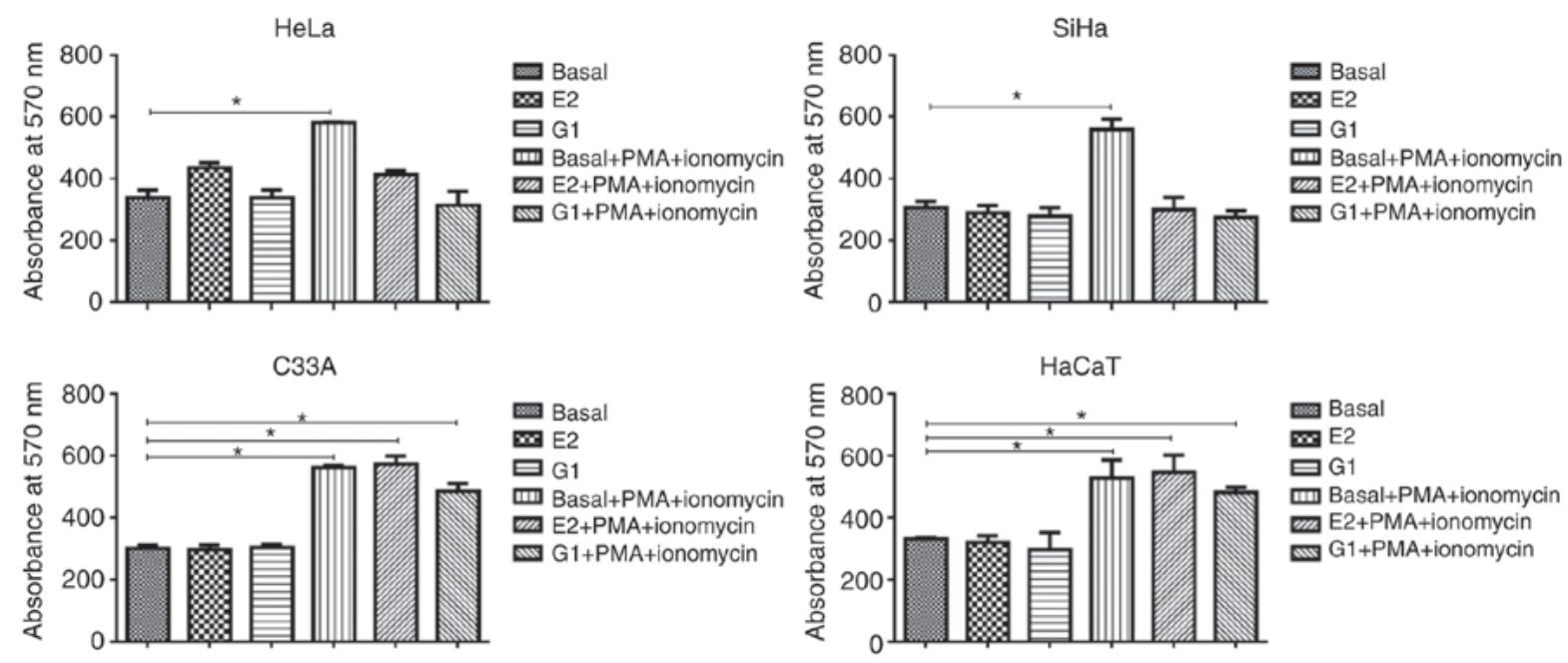

Figure 2. E2 affects the calcium regulation in cervical cancer cells. $\mathrm{Ca}^{2+}$ levels were determined in $\mathrm{HeLa}$, SiHa and C33A cervical cancer cells and HaCaT following various treatments. Experiments were performed in triplicate and with three repeats. "P<0.05. E2, 17 $\beta$-estradiol; PMA, 1,1,3,3-tetramethoxypropane; G1, 1-[4-(6-bromobenzo[1,3]dioxol-5yl)-3a,4,5,9b-tetrahydro-3H-cyclopenta[c]quinolin-8-yl]-ethanone.

cofactors, as well as on the metabolism of amino acids, nucleotides, phosphatidylinositol and choline (Table I). E2 regulated the expression of genes involved in mitochondrial complexes as follows: (i) Complex I, NDUFAB1, NDUFA4, and NDUFS5 upregulated; (ii) complex III, $U Q C R B$ and $U Q C R H$ upregulated; (iii) complex IV, $C O X 6 C, C O X 5 B, C O X 7 C, C O X 7 B$ and COX6A1 upregulated; (iv) complex V, ATP5F1A, ATP5F1E, $A T P 5 F 1 B, A T P 5 M C 2, A T P 5 M G, A T P 5 P B$ and ATP5PO upregulated, and TCIRG1 downregulated.

Absolute changes in DEGs ranged between -0.4985 and 0.2496 . A total of 5 genes associated with glycolysis were modified in both HeLa and $\mathrm{SiHa}$ by E2 stimulus, including LDHA, LDHB, PGK1, TPII and PFKP (absolute changes, -0.1893 to 0.2598$)$. Other gene alterations modulated by E2 include: (i) Metabolism and synthesis of glycans $(\mathrm{n}=10)$, with GAA, NDST1, SGSH, PIGQ, MGAT5B, GPAAl and MGAT1 downregulated and EXT1, PIGK and TUSC3 upregulated; (ii) lipid metabolism (n=10), with MGAT1, AGPS, FASN, $A C A D V L, C A D$ and SPHK1 upregulated and CPS1, PTGES3, PLA2G4A and PPT1 downregulated; (iii) metabolism of amino acids and nucleotides (n=9); (iv) metabolism of inositol phosphate $(\mathrm{n}=4)$; and (v) metabolism of choline, vitamins and cofactors ( $n=3$; Table II and Fig. 8).

A total of 12 signaling pathways were affected by E2, including hypoxia-inducible factor (HIF)-1, Ras, mitogen-activated protein kinase (MAPK), vascular endothelial growth factor (VEGF), phospholipase D, 5'-AMP-activated protein kinase (AMPK), cGMP-dependent protein kinase (PKG), 

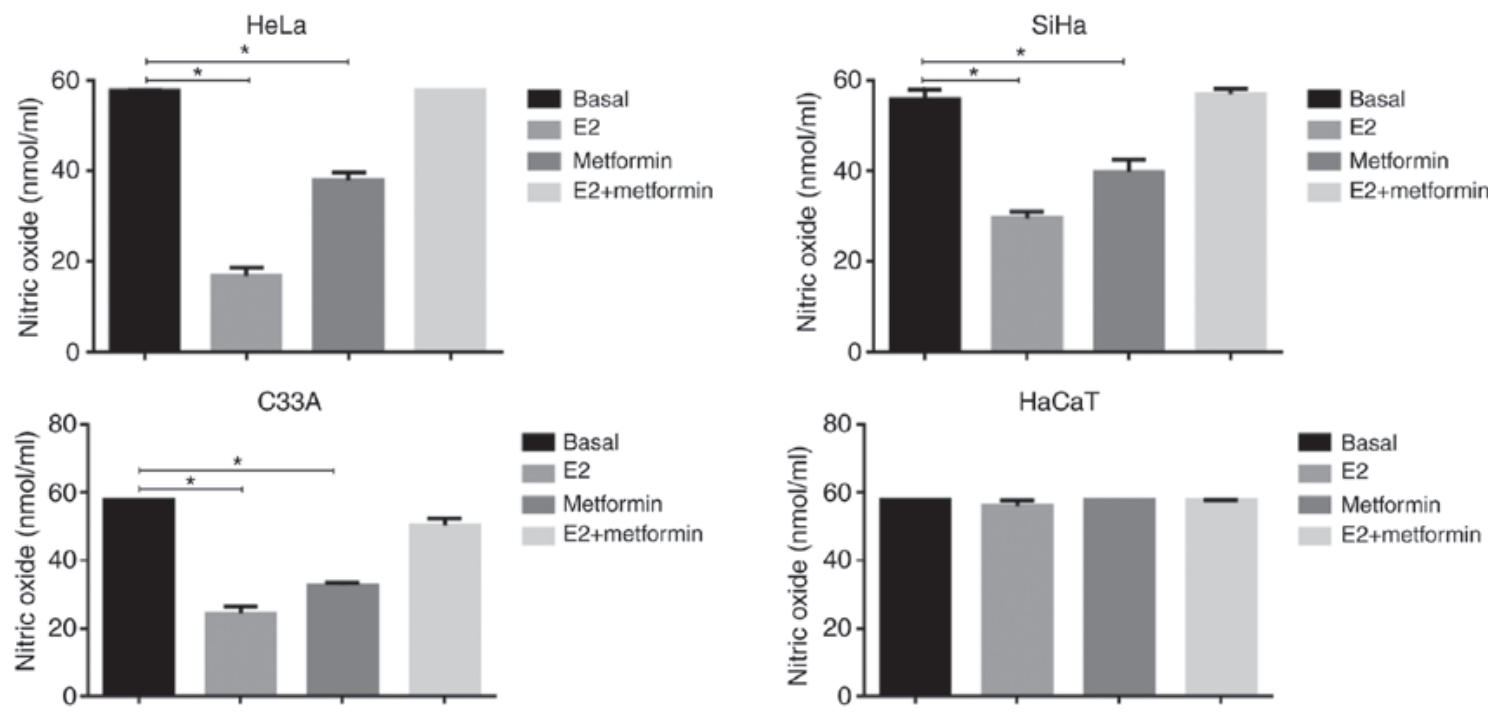

Figure 3. E2 affects nitric oxide production in cervical cancer cells. Nitric oxide levels were determined in HeLa, SiHa and C33A cervical cancer cells and $\mathrm{HaCaT}$ following various treatments. Experiments were performed in triplicate and with three repeats. ${ }^{*} \mathrm{P}<0.05$. E2, 17ß-estradiol.
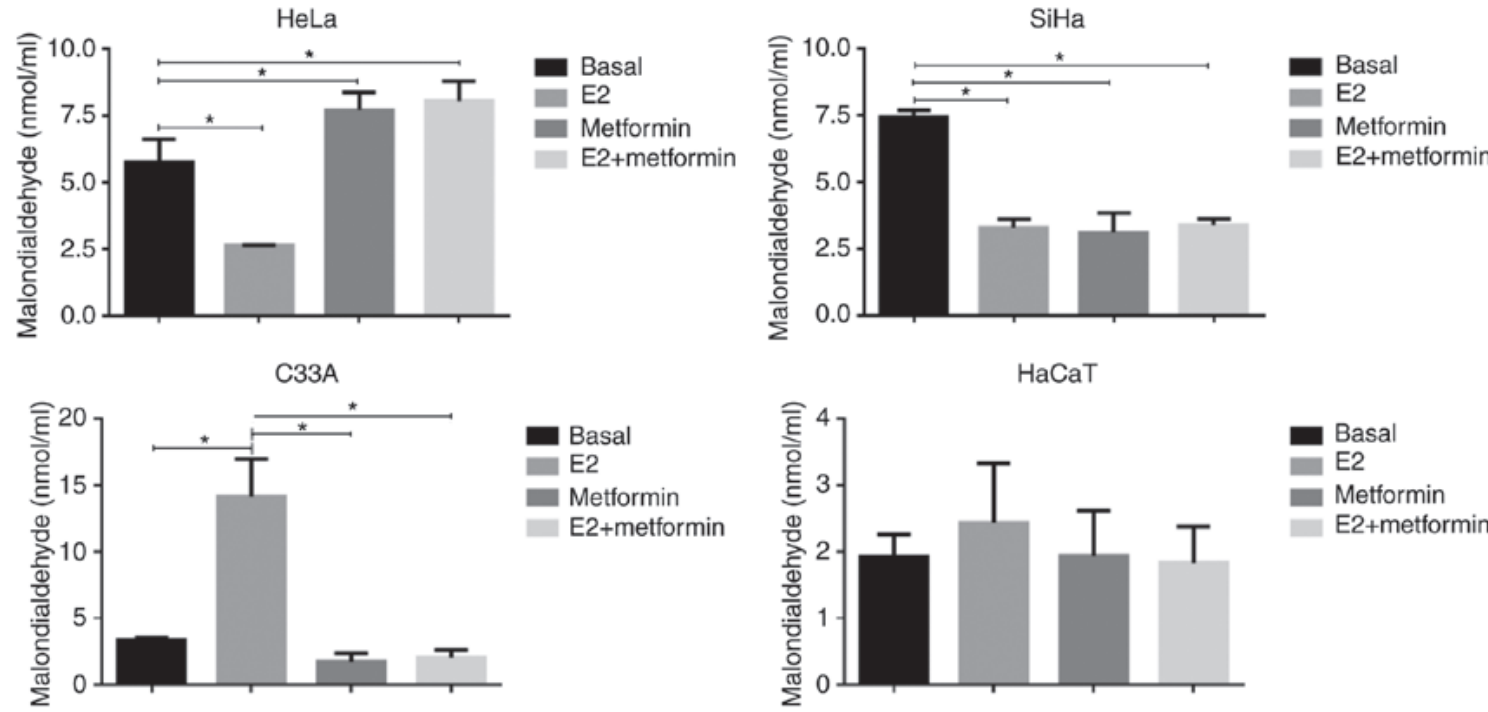

Figure 4. E2 affects lipid peroxidation in cervical cancer cells. Lipid peroxide levels were determined in HeLa, SiHa and C33A cervical cancer cells and HaCaT following various treatments. Experiments were performed in triplicate and with three repeats. " $\mathrm{P}<0.05$. E2, $17 \beta$-estradiol.
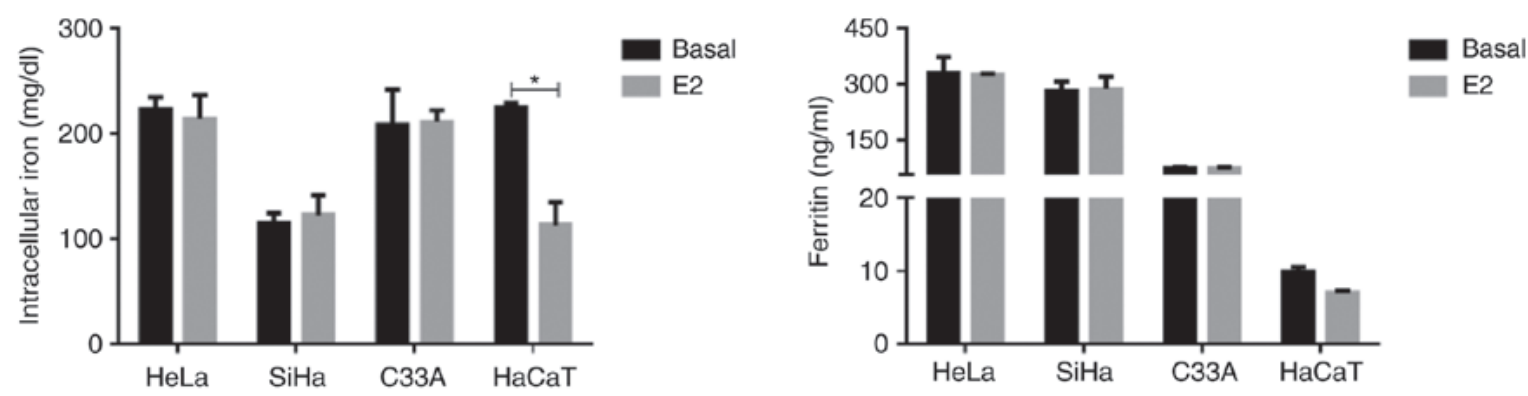

Figure 5. E2 affects the iron metabolism in cervical cancer cells. Intracellular iron and ferritin levels were determined in HeLa, SiHa and C33A cervical cancer cells and $\mathrm{HaCaT}$ following E2 treatment. Experiments were performed in triplicate and with three repeats. ${ }^{*} \mathrm{P}<0.05$. E2, $17 \beta$-estradiol.

calcium, appeline, phosphatidylinositol, PI3K-Akt and pathways mediated by sphingolipid (Table III). It should be noted that of these, genes that affected HIF-1, Ras, MAPK, VEGF and phospholipase $\mathrm{D}$ pathways that were upregulated included PGK1, LDHA and PLA2G4A (absolute changes, 0.1606, 0.2167 and 0.2494 , respectively). Decreased genes following 

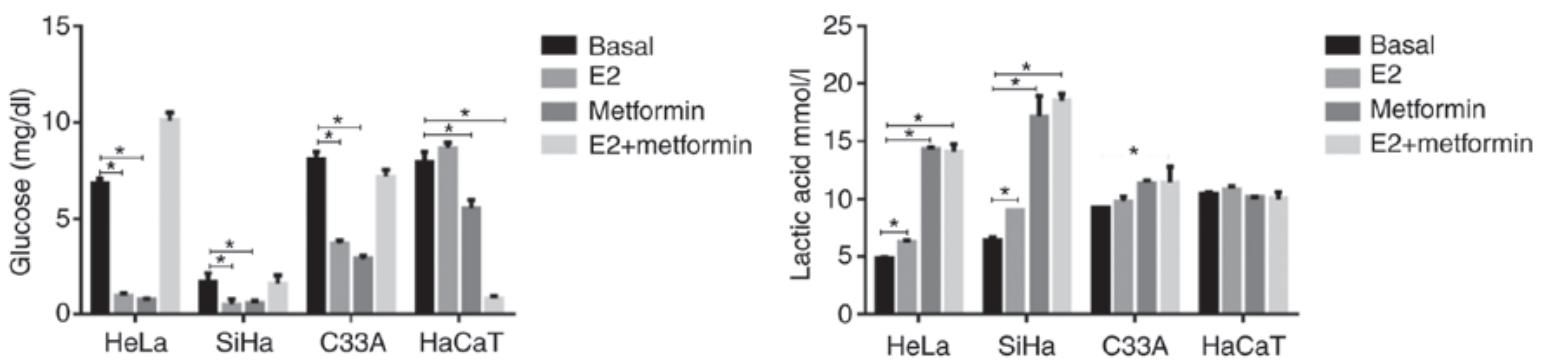

Figure 6. E2 affects the Warburg effect in cervical cancer cells. Glucose and lactic acid ferritin levels were determined in HeLa, SiHa and C33A cervical cancer cells and HaCaT following E2 treatment. Experiments were performed in triplicate and with three repeats. ${ }^{*} \mathrm{P}<0.05$. E2, 17 $\beta$-estradiol.

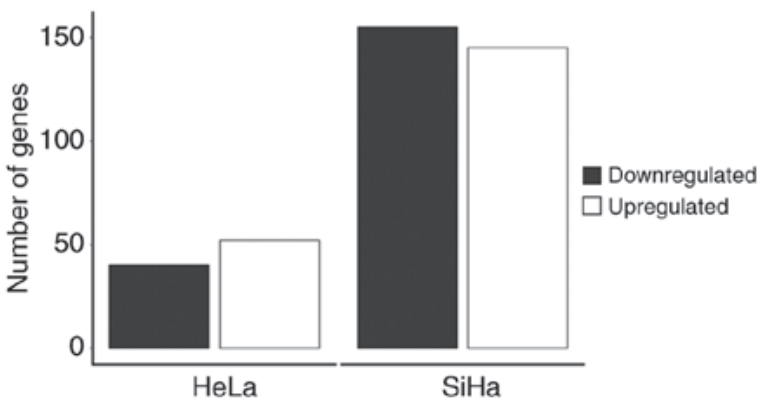

Figure 7. E2 affects expression of genes belonging to metabolic pathways in $\mathrm{HeLa}$ and $\mathrm{SiHa}$. All experiments were performed in duplicate four times. E2, 17ß-estradiol; DEG, differentially expressed gene.

E2 stimulus included PFKP (-0.1893), FASN (-0.5459), CAD (-0.3228), SPHK1 (-0.3164), PLCD3 (-0.5829), INPPL1 (-0.7263) and LAMA5 (-0.7294), corresponding to the AMPK, cGMP-PKG, calcium, sphingolipid-mediated, appeline, phosphatidylinositol and PI3K-Akt signaling pathways (Table III).

Fig. 8 outlines important DEGs regulated by E2 and those directly involved in mitochondrial function, metabolism and associated signaling pathways. The impact of E2 in the pathophysiology of cervical cancer was suggested to be associated with the dysregulation of the respiratory mitochondrial electron chain, increasing OXPHOS, and activating glycolysis and the pentose phosphate pathway (Warburg effect). E2 was also suggested to inhibit the degradation of amino acids and provide metabolites for the synthesis of nucleotides, nucleic acids and coenzymes. Furthermore, it was hypothesized that E2 stimulates the synthesis of fatty acids associated with steroids, leukotrienes and prostaglandins metabolites, while it reduces the $\beta$-oxidation of lipids. It was suggested that $\mathrm{E} 2$ reduces oxidized glutathione, which regulates the oxidative state of tumor cells.

E2 does not modify metformin antiproliferative effect. Metformin is proposed as an antitumor drug (26). The most relevant mechanism of its activity is the regulation of cellular metabolism (27). The potential role of $\mathrm{E} 2$ in metformin-induced cell death in cervical cancer was assessed in this study. In cervical cancer cells treated with metformin a significant decrease in proliferation was observed compared with the basal control at incubation times $>20 \mathrm{~h}(\mathrm{P}=0.0001$; Fig. 9). In $\mathrm{HeLa}$, the effect of metformin was similar to that induced by cisplatin, thus metformin was suggested to be a potential anticarcinogen. E2 treatment did not markedly alleviate effects exerted by metformin.

\section{Discussion}

Chronic and excessive exposure to estrogen is associated with an increased cancer risk incidence and the classical mechanism to explain this association is that estrogen affects the cell proliferation (28). Previously, effects of E2 on the mitochondrial metabolism were shown by increased mitochondrial activity based on MTT assays, which are known to alter the complex IV levels and therefore inferred a modification in mitochondrial metabolism (3). However, in this study we approached other aspects associated with this alteration in cervical cancer, such as the influence of the hormone in mitochondrial permeability, calcium mobilization, NO levels, the Warburg effect and modifications of pathways important in tumorigenesis.

The presence of E2 decreased the mitochondrial membrane permeability, which was in response to several factors, such as calcium concentration, oxidative stress and ATP depletion. It has been shown that estrogen affects the mitochondrial function through the modulation of $\mathrm{Ca}^{2+}$ levels. Excessive $\mathrm{Ca}^{2+}$ loading coupled with oxidative stress triggers a collapse of the mitochondrial membrane potential $(\Delta \psi \mathrm{m})$ accompanied by edema of the matrix and initiation of apoptosis due to the release of cytochrome c (10). E2 protects mitochondria by preventing $\Delta \psi \mathrm{m}$ collapse and this may explain the described ability of estrogen to prevent the release of apoptotic factors (8). Intracellular calcium signals are critical for mitochondrial-nuclear crosstalk and the maintenance of cellular homeostasis (12). In the central nervous system, E2 exhibits neuroprotective characteristics preventing the influx of cytosolic and mitochondrial $\mathrm{Ca}^{2+}$ during excitotoxic stimulation $(9,10)$. Additionally, the repression of $\mathrm{Ca}^{2+}$ mobilization by E2 may serve to protect cells from death during oxidative stress. In previous studies, it was observed that the use of E2 inhibits the effect of $\mathrm{Ca}^{2+}$ levels on pro-oxidant substances, such as 3-nitropropionic acid and $\mathrm{H}_{2} \mathrm{O}_{2}(9,11)$. In the present study, E2 inhibited the response induced by ionomycin and PMA with regards to the mobilization of calcium and it was hypothesized that E2 caused alterations in the calcium signaling pathway. Furthermore, the results suggested that E2 may protect cervical cancer cells.

$\mathrm{NO}$ is a well-known intracellular messenger in a range of physiological processes and a regulator of cell death and survival. It modulates apoptotic pathways and long-term exposure to $\mu$ molar NO can induce cell death by apoptosis $(13,28)$. When NO is combined with superoxide radicals, it generates compounds, such as peroxynitrite, that lead to irreversible 


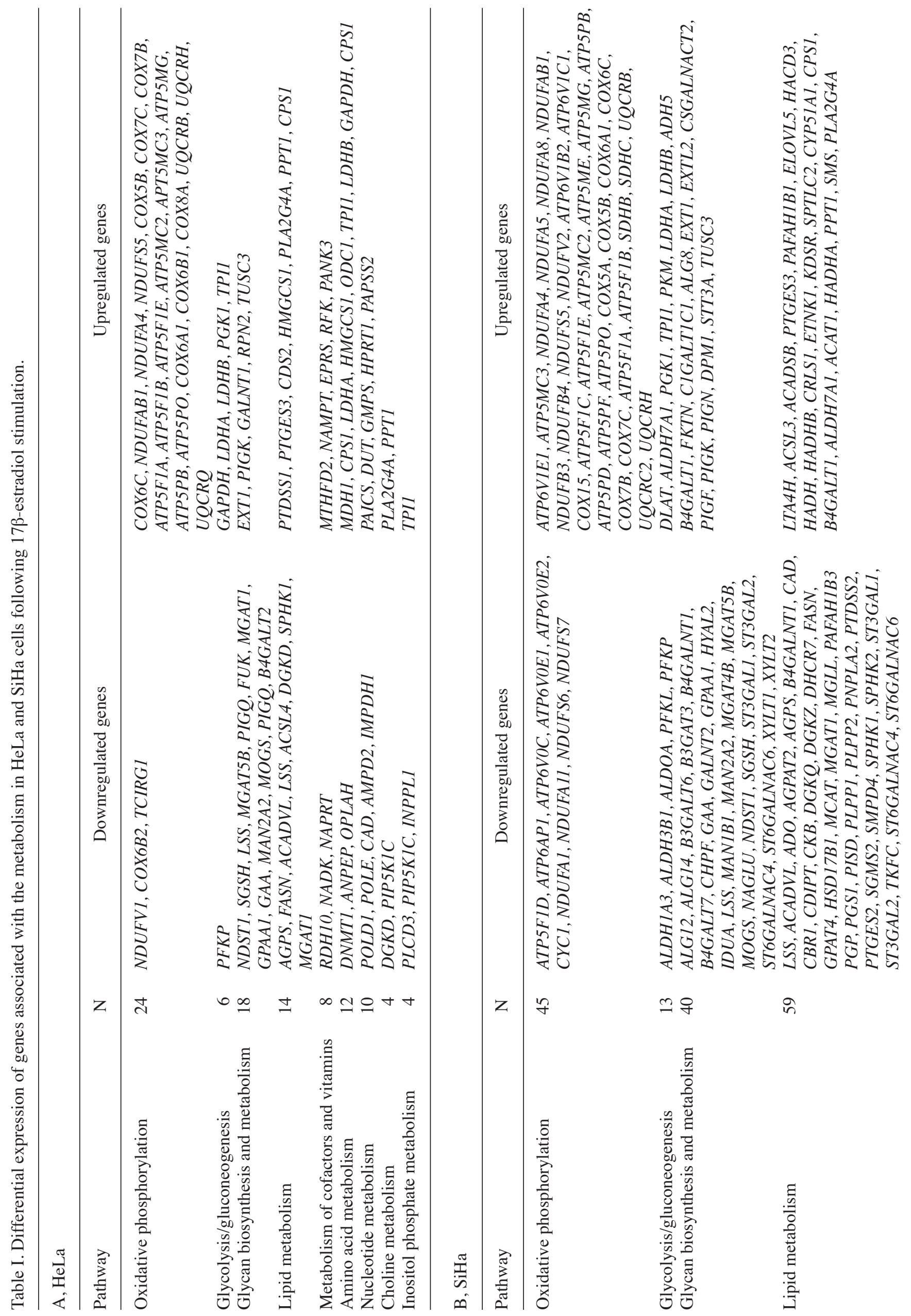


protein nitration, enzymatic inactivation, DNA damage, disruption of the mitochondrial integrity and cell apoptosis either by direct contact or by inducing lipid peroxidation (29). It has been reported that $\mathrm{E} 2$ has an antioxidant mechanism by increasing a blockage of the sensitivity of mitochondria to calcium, enhancing antioxidant systems and decreasing the expression of NO synthetase (10-12,30-32); this may explain why no lipid peroxidation was observed in $\mathrm{HeLa}$ and $\mathrm{SiHa}$. However other mechanisms may further be involved. The protective effect of $\mathrm{E} 2$ on the survival of the cervical cancer cells was demonstrated in our study by reporting a decrease in NO levels following E2 stimulus.

Excessive iron availability in mitochondria exacerbates oxidative stress and promotes membrane lipid peroxidation, affecting the integrity of the inner mitochondrial membrane and the mitochondrial function (33). Several studies showed the participation of estrogen in iron metabolism. In general, the hormone appears to protect the cells from a distinct nonapoptotic cell death (ferroptosis) because it lowers the levels of iron and ferritin, and it regulates the expression of other proteins that participate in iron metabolism (22,34-36). This effect was not observed in the present study, as we did not find any significant impact of E2 on iron and ferritin levels in cervical cancer cells. It is known that for rapid proliferation, cells enhance metabolic activity allowing for increased DNA biosynthesis; this may describe why HaCaT cells to have high iron levels and require less ferritin. However, in $\mathrm{SiHa}$, oxidative stress may be controlled through maintaining lower free iron levels, as intracellular iron may be harmful due to its ability to produce ROS (37-40).

The metabolic networks that give rise to metabolic phenotypes in most tumors are unknown. In this study, an essential role of E2 favoring the Warburg effect was demonstrated. It increased the glucose consumption and lactic acid levels in cervical cancer cell lines. Glucose utilization provides tumor cells with a constant energy supply, as well as precursors for de novo macromolecular biosynthesis that are essential for cell growth and proliferation (13). Estrogen substantially increased the glycolytic activities and glucose utilization in the uterus of ovariectomized rats in concert with the uterine growth (41). The hormone increases the glucose uptake in muscle and adipose tissues through the regulation of the expression of the glucose transporter 4 and decreases gluconeogenesis in the liver $(36,42)$.

Although the Warburg effect predominantly focuses on glycolysis and suggesting attenuation in the mitochondrial metabolism, more recent works suggested that certain TCA cycle intermediates are elevated and important in the context of cancer (43-45). Thus, while glycolysis is drastically upregulated in most cancer cells, mitochondrial respiration continues to operate normally at rates proportional to oxygen supply.

To gain a better understanding of estrogen effects in the metabolism of cervical cancer, we performed a detailed analysis of the metabolic gene expression modulated by E2 in $\mathrm{SiHa}$ and HeLa cells, which are representative of $~ 99 \%$ of cervical tumors (46). E2 upregulated various genes associated with the protein components of the electron respiratory chain complexes. Consistent with these observations, previous work suggested that female liver mitochondria have greater capabilities of OXPHOS than the mitochondria from 
Table II. Differentially expressed genes shared by HeLa and SiHa associated with the metabolism following stimulation with $17 \beta$-estradiol.

\begin{tabular}{llll}
\hline Pathway & N $\quad$ Downregulated genes & Upregulated genes
\end{tabular}

Oxidative phosphorylation

19 TCIRG1

Glycolysis/gluconeogenesis

Glycan biosynthesis and metabolism

Lipid metabolism

Metabolism of cofactors and vitamins

Amino acid metabolism

Nucleotide metabolism

Choline metabolism

Inositol phosphate metabolism
$5 \quad P F K P$

10 GAA, NDST1, SGSH, PIGQ, EXT1, PIGK, TUSC3

MGAT5B, GPAA1, MGAT1

10 MGAT1, AGPS, FASN,

$A C A D V L, C A D, S P H K 1$

$3 N A D K, N A P R T$

9 ANPEP, OPLAH, CAD

9 FUK, POLD1, AMPD2, IMPDH1, PFAS

3 PIP5K1C

4 PLCD3, PIP5K1C, INPPL1

EPRS

PLA2G4A, PPT1

TPII
COX6C, NDUFAB1, NDUFA4, NDUFS5, COX5B, COX7C, COX7B, ATP5F1A, ATP5F1B, ATP5F1E, ATP5MC2, ATP5MG, ATP5PB, ATP5PO,

COX6A1, UQCRB, UQCRH, MDH1

LDHA, LDHB, PGK1, TPII

CPS1, PTGES3, PLA2G4A, PPT1

MDH1, LDHA, LDHB, ODC1, PGK1, TPI1, CPS1

PAICS, GMPS, HPRT1, NME1

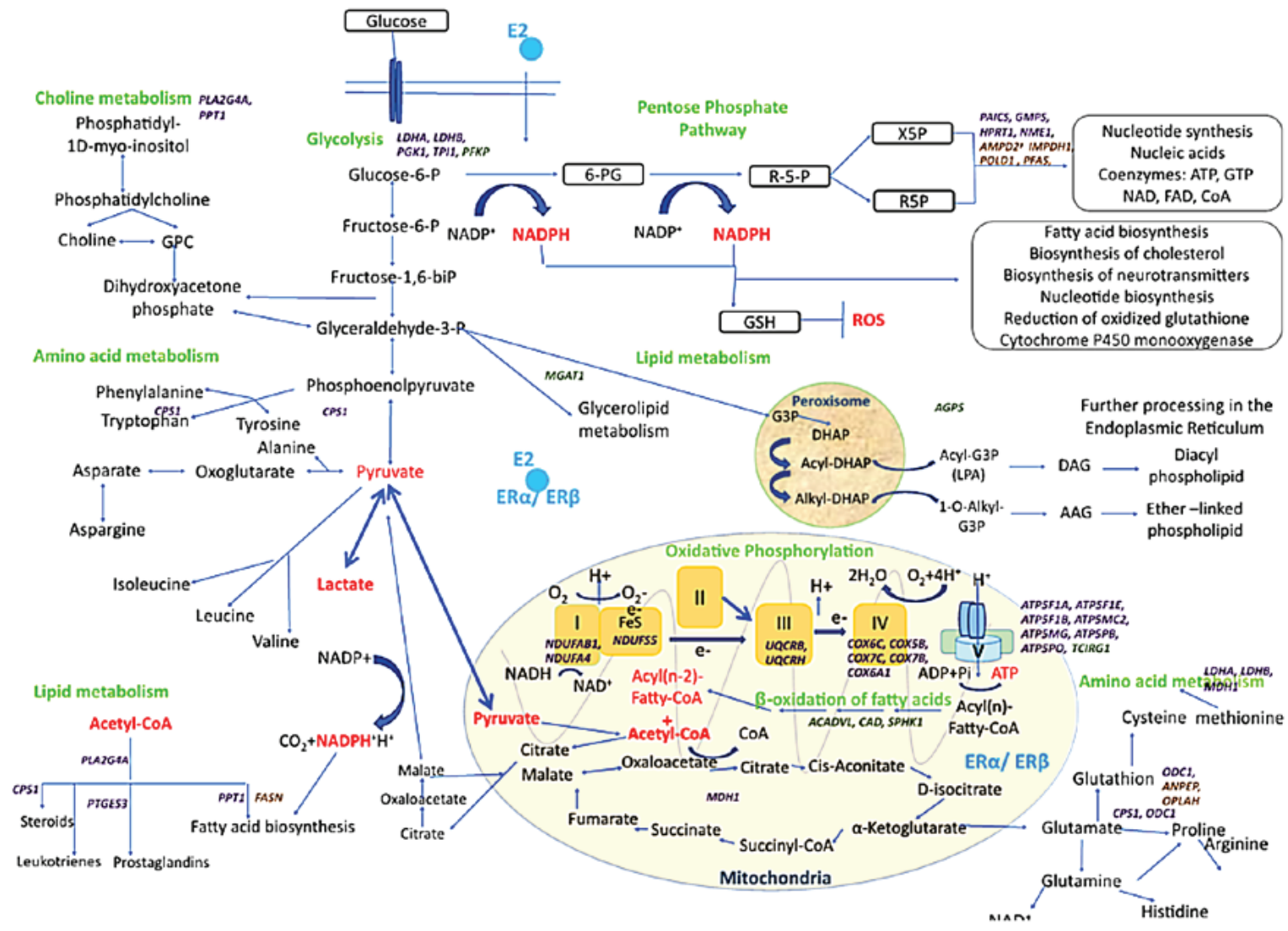

Figure 8. Schematic representation of the involvement of E2 in metabolic pathways in HeLa and SiHa cells; with upregulated genes in purple, downregulated genes in brown, metabolic intermediates and enzymes in red, metabolic pathways in light green and hormone receptors in blue. E2, 17 $\beta$-estradiol; ER, estrogen receptor; ROS, reactive oxygen species.

males (47). Mitochondrial (mt) DNA contains sequences similar to the estrogen response element (ERE) and glucocorticoid responsive elements (48). Chen et al (49) observed that recombinant human $\mathrm{ER} \alpha$ and $\mathrm{ER} \beta$ bind to mtEREs and this binding is enhanced by E2. Studies in which MTT is used, reported an increase in the conversion of MTT to formazan in the presence of E2 $(50,51)$. Furthermore, nuclear genes that participate in the transcription of proteins of the respiratory 
Table III. Differentially expressed genes affecting signaling pathways associated with metabolism shared by HeLa and SiHa after stimulation with $17 \beta$-estradiol.

A, Downregulated genes

\begin{tabular}{llc}
\hline Signaling pathway & \multicolumn{1}{c}{ Gene } & P-value \\
\hline VEGF & SPHK1 & $1.6706 \times 10^{-2}$ \\
Phospholipase D & SPHK1 & $1.6706 \times 10^{-2}$ \\
& PIP5K1C & $7.1061 \times 10^{-3}$ \\
AMPK & PFKP & $1.0293 \times 10^{-2}$ \\
& FASN & $1.2382 \times 10^{-34}$ \\
cGMP-PKG & CAD & $1.5215 \times 10^{-4}$ \\
Calcium & SPHK1 & $1.6706 \times 10^{-2}$ \\
& PLCD3 & $8.8258 \times 10^{-7}$ \\
Sphingolipid & SPHK1 & $1.6706 \times 10^{-2}$ \\
Apelin & SPHK1 & $1.6706 \times 10^{-2}$ \\
Phosphatidylinositol & PLCD3 & $8.8258 \times 10^{-7}$ \\
& PIP5K1C & $7.1062 \times 10^{-3}$ \\
& INPPL1 & $1.7603 \times 10^{-11}$ \\
PI3K-Akt & LAMA5 & $1.1881 \times 10^{-85}$ \\
\hline
\end{tabular}

B, Upregulated genes

\begin{tabular}{llc}
\hline Signaling pathway & Gene & P-value \\
\hline HIF-1 & PGK1, & $4.7152 \times 10^{-4}$ \\
& LDHA & $6.4214 \times 10^{-7}$ \\
Ras & $P L A 2 G 4 A$ & $9.7518 \times 10^{-3}$ \\
MAPK & $P L A 2 G 4 A$ & $9.7518 \times 10^{-7}$ \\
VEGF & PLA2G4A & $9.7518 \times 10^{-7}$ \\
Phospholipase D & PLA2G4A & $9.7518 \times 10^{-7}$ \\
\hline
\end{tabular}

chain of electrons are suggested to be modulated by estrogen. The expression of the genes involved in mitochondrial ATP synthase subunit $\beta$ and $\mathrm{F}$ complex is upregulated by E2 in prostatic dysplasia (52), and the subunit $\mathrm{c}$ isoform of the F0 complex and mitochondrial ribosomal protein 3 are other nuclear estrogen-regulated genes identified in ER $\alpha$-positive breast cancer cells (53).

In neuroblastoma, E2 has a protective effect against ATP depletion, $\Delta \psi \mathrm{m}$ decline and the generation of ROS induced by an inhibitor of the succinate dehydrogenase complex (54). There is potential that E2 mediated these effects via stimulating the synthesis of protein components of the electron respiratory chain complexes, and contributed to the preservation and regulation of the mitochondrial structure and functions. The presence of ERs has been associated with the preservation of ATP levels via enhancing OXPHOS and reducing ATPase activity, and thus, increasing mitochondrial respiration efficiency in neurons (55).

In association with these effects, E2 enhances the antioxidant systems in the brain by inducing the expression of glutathione, thioredoxin and superoxide dismutase proteins $(30,32)$. With these observations and the findings reported in our bioenergetics analysis at the gene level, we hypothesized that in cervical cancer, E2 protects tumor cells from stress-induced death during malignant transformation partially by modulating mitochondrial respiratory chain structure and function.

Mitochondrial alterations as part of the adaptation of tumor cells to their microenvironment favor the Warburg effect (43). In this study, E2 modulated numerous genes associated with an increase in the expression of glycolytic proteins. The only gene downregulated by the hormone shared by HeLa and $\mathrm{SiHa}$ in this metabolic pathway was PFKP. The conversion of fructose-6-phosphate to fructose-1,6-bisphosphate catalyzed by phosphofructokinase-1 is the most important control step in mammalian glycolysis $(56,57)$. Downregulation of PFKP potentiates cancer cell survival under metabolic stress through the maintenance of pentose phosphate pathway flow (57). Dynamic regulation of glucose flux between aerobic glycolysis and the pentose phosphate pathway provides the tumor cell with the metabolites needed to proliferate. NADPH production is an important strategy against oxidative stress and oxidative stress, not ATP depletion, is the primary trigger of cell death during metabolic stress (57). Downregulation of PFKP by E2 constituted a transcendent mechanism of evasion of cell death in difficult situations.

Our bioinformatics analysis suggested other metabolic pathways modulated by E2. Abnormal choline metabolism has emerged as a hallmarks of cancer, and increases in choline kinase- $\alpha$ expression and activity, a higher rate of choline transport and increased phosphatidylcholine-specific phospholipase $\mathrm{C}$ and $\mathrm{D}$ activities have been well documented within the pathophysiology of several cancers (57). The aberrant choline phospholipid metabolism of breast cancer cells and its correlation with the malignant progression has been reported (58). In our study, E2 was suggest to upregulate the expression of enzymes associated with the metabolism of choline and other lipids, which can affect the cholesterol metabolism and the synthesis of steroids, prostaglandins and leukotrienes. Physiologically, it has been reported that estrogen, in general, inhibits de novo lipogenesis in the liver (59), but increase cholesterol biosynthesis for cell proliferation (60).

In one study, a metabolomics approach for evaluating the estrogenic effects in uterus established that the TCA cycle, lipid metabolism, choline and amino acid metabolisms are disturbed (61). The reported alterations dependent on the ERs include: (i) Phenylalanine, tyrosine and tryptophan biosynthesis; (ii) alanine, aspartate, glutamate, glycerophospholipids and pyruvate metabolism; (iii) the citrate cycle; and (iv) glycolysis or gluconeogenesis. These observations are in accordance with our results and led to the hypothesis that E2 may exert physiological functions in an erroneous context within the pathophysiology of cervical cancer.

Another remarkable finding of our work was that E2 modulated signaling pathways that are essential for metabolism and tumorigenesis. The role of HIF-1 (62) and Ras-MAPK in the metabolism of cancer has been well documented $(63,64)$. AMPK is a pivotal intracellular energy sensor in normal and tumor cells. Studies have been reported that high glucose levels reduce AMPK phosphorylation and activate the MAPK signaling pathway in cancer cells $(64,65)$. Inactivation of AMPK accelerates tumorigenesis (66). There are no conclusive 

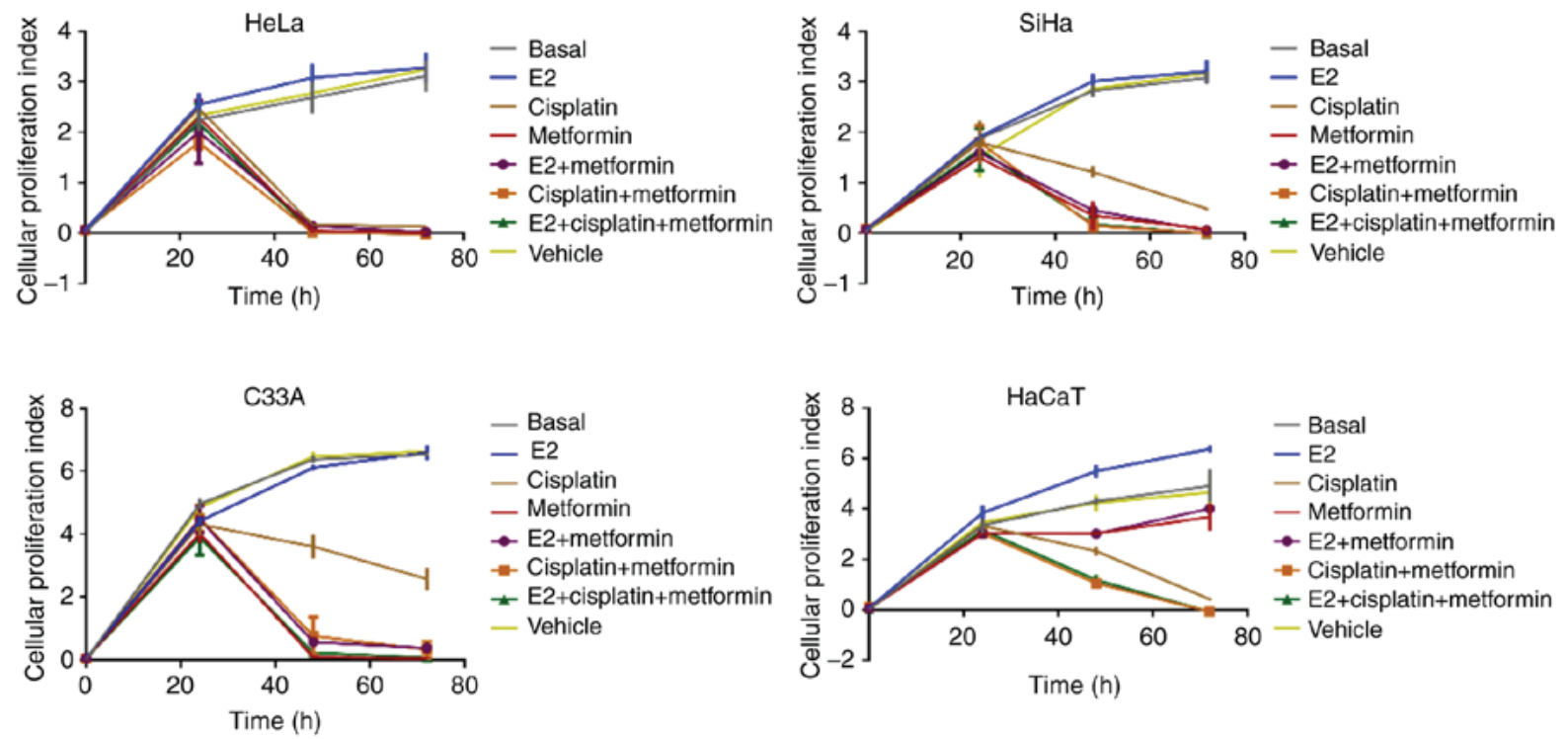

Figure 9. Effects of E2 and metformin on proliferation of cervical cancer cells. Proliferation of HeLa, SiHa, C33A and HaCaT cells is presented for $24 \mathrm{~h}$ intervals over $72 \mathrm{~h}$ following various treatments. Cisplatin was used as a cell death control. Experiments were performed in triplicate and with three repeats. E2, $17 \beta$-estradiol.

results about the effects of estrogen on AMPK expression in different tumors; some evidence suggests AMPK activation by $\operatorname{ER} \alpha(67)$, while other evidence considers that the hormone inhibits AMPK by repressing the expression of its activating proteins (68). Interestingly, our study showed that E2 was suggested to decrease the expression of genes that indirectly repress AMPK.

Further observation of this work included that E2 modulated the differential expression of several genes associated with metabolic pathways. The number of DEGs in SiHa was 3 times greater than in HeLa; this may be explained due to these cells being derived from different epithelial cells (squamous cell carcinoma and adenocarcinoma) and that they are infected by two different virus genotypes (16 and 18 , respectively) that may modify DEGs involved in signaling pathways, and therefore, affected pathogenicity mechanisms and treatment responses. Furthermore, our results indicated that, although from the same anatomical site, SiHa and HeLa displayed marked differences following treatment with E2. Regional differences in HPV genotypes may affect DEGs and the phenotype of the cervical cells. The difference in HPV genotype leads to different treatment responses with different clinical characteristics, pathogenicity mechanisms and histopathological subtypes (69). These results are essential for the design of new therapeutic models against cervical cancer.

Metformin has gained considerable attention as a potential anticancer agent. One of its main mechanisms of action is the suppression of the mitochondrial respiration by inhibiting the respiratory complex I (70). In human breast adipose stromal cells, it activates the liver kinase B1-AMPK signaling pathway and inhibits aromatase expression (71). Furthermore, the negative modulation of metformin on ERs, in particular ER $\alpha$, has been demonstrated in numerous studies (72-74). In this work, the effect of metformin on E2 metabolic actions was evaluated. There are specific molecular features that control the uptake of biguanides into mitochondria (70), so we suggested that modifications in the mitochondrial permeability by E2 may be another factor that conditioned the entry of metformin in the organelle. In addition, although there are no specific transporters for biguanides, uptake is tissue-specific due to varying levels of distinct transporter expression (70). This evidence supported the different effects of metformin in the metabolic regulation of various cell lines, even when derived from the same type of tumor.

Measuring the metabolic responses of cervical cancer cell lines to E2 stimulus, allowed us to identify a distinct bioenergetics phenotype in cervical cancer that was the result of alterations in OXPHOS and the glycolytic energy metabolism. We concluded that E2 induced changes in the energy metabolism that allowed cell survival in high-stress conditions. The antioxidant and cytoprotective power of E2 in the context of cancer was demonstrated in this work.

\section{Acknowledgments}

Not applicable.

\section{Funding}

This work was supported by CB 2017-2018 CONACYT (grant no. A1-S-51207) and the Health Research Fund from IMSS (grant no. FIS/IMSS/PROT/PRIO/15/046).

\section{Availability of data and materials}

The datasets used and/or analyzed during the current study are available from the corresponding author on reasonable request.

\section{Authors' contributions}

ARL and PCOL performed the experimental work, searched for scientific literature, contributed to figures and the writing of the manuscript. LFJS, ARdA and JFMV participated in 
contributed to the data analysis and reviewed the manuscript. AAL, YMOG, CABG, RSM and SLdA performed experiments. APS conceived and designed the study and wrote the manuscript. All authors read and approved the final manuscript.

\section{Ethics approval and consent to participate}

Not applicable.

\section{Patient consent for publication}

Not applicable.

\section{Competing interests}

The authors declare that they have no competing interests.

\section{References}

1. Chen Q, Cao HZ and Zheng PS: LGR5 promotes the proliferation and tumor formation of cervical cancer cells through the Wnt/ $\beta$-catenin signaling pathway. Oncotarget 5: 9092-9105, 2014.

2. Chung SH, Wiedmeyer K, Shai A, Korach KS and Lambert PF Requirement for estrogen receptor alpha in a mouse mode for human papillomavirus-associated cervical cancer. Cancer Res 68: 9928-9934, 2008

3. Riera-Leal A, Ramirez De Arellano A, Ramirez-Lopez IG, Lopez-Pulido EI, Davila Rodriguez JR, Macias-Barragan JG, Ortiz-Lazareno PC, Jave-Suárez LF, Artaza-Irigaray C, Del Toro Arreola S, et al: Effects of $60 \mathrm{kDa}$ prolactin and estradiol on metabolism and cell survival in cervical cancer: Coexpression of their hormonal receptors during cancer progression. Oncol Rep 40: 3781-3793, 2018

4. Otto AM: Warburg effect(s)-a biographical sketch of otto warburg and his impacts on tumor metabolism. Cancer Metab 4 $5,2016$.

5. Asgari Y, Zabihinpour Z, Salehzadeh-Yazdi A, Schreiber F and Masoudi-Nejad A: Alterations in cancer cell metabolism: The warburg effect and metabolic adaptation. Genomics 105 275-281, 2015.

6. Wu M, Neilson A, Swift AL, Moran R, Tamagnine J, Parslow D, Armistead S, Lemire K, Orrell J, Teich J, et al: Multiparameter metabolic analysis reveals a close link between attenuated mitochondrial bioenergetic function and enhanced glycolysis dependency in human tumor cells. Am J Physiol Cell Physiol 292: C125-C136, 2007

7. Chen JQ, Yager JD and Russo J: Regulation of mitochondrial respiratory chain structure and function by estrogens/estrogen receptors and potential physiological/pathophysiological implications. Biochim Biophys Acta 1746: 1-17, 2005.

8. Paterni I, Granchi C, Katzenellenbogen JA and Minutolo F: Estrogen receptors alpha $(\mathrm{ER} \alpha)$ and beta $(\mathrm{ER} \beta)$ : Subtype-selective ligands and clinical potential. Steroids 90: 13-29, 2014.

9. Chen JQ, Cammarata PR, Baines CP and Yager JD: Regulation of mitochondrial respiratory chain biogenesis by estrogens/estrogen receptors and physiological, pathological and pharmacological implications. Biochim Biophys Acta 1793: 1540-1570, 2009.

10. Simpkins JW, Yang SH, Sarkar SN and Pearce V: Estrogen actions on mitochondria-physiological and pathological implications. Mol Cell Endocrinol 290: 51-59, 2008.

11. Ribas V, Drew BG, Zhou Z, Phun J, Kalajian NY, Soleymani T, Daraei P, Widjaja K, Wanagat J, de Aguiar Vallim TQ, et al: Skeletal muscle action of estrogen receptor alpha is critical for the maintenance of mitochondrial function and metabolic homeostasis in females. Sci Transl Med 8: 334ra54, 2016.

12. Lobaton CD, Vay L, Hernandez-Sanmiguel E, Santodomingo J, Moreno A, Montero M and Alvarez J: Modulation of mitochondrial $\mathrm{Ca}(2+)$ uptake by estrogen receptor agonists and antagonists. Br J Pharmacol 145: 862-871, 2005.

13. Palsson-McDermott EM and O'Neill LA: The Warburg effect then and now: From cancer to inflammatory diseases. BioEssays 35: 965-973, 2013.
14. Liu YQ, Zhang GA, Zhang BC, Wang Y, Liu Z, Jiao YL, Liu N and Zhao YR: Short low concentration cisplatin treatment leads to an epithelial mesenchymal transition-like response in DU145 prostate cancer cells. Asian Pac J Cancer Prev 16: 1025-1028, 2015.

15. Chen Y, Wang S, Bu S, Xu M and Lai D: Low-dose cisplatin-induced CXCR4 expression promotes proliferation of ovarian cancer stem-like cells. Acta Biochim Biophys Sin (Shanghai) 48: 282-289, 2016.

16. Dodt M, Roehr JT, Ahmed R and Dieterich C: FLEXBAR-flexible barcode and adapter processing for next-generation sequencing platforms. Biology (Basel) 1: 895-905, 2012.

17. Bray NL, Pimentel H, Melsted P and Pachter L: Near-optimal probabilistic RNA-seq quantification. Nat Biotechnol 34: 525-527, 2016.

18. Love MI, Huber W and Anders S: Moderated estimation of fold change and dispersion for RNA-seq data with DESeq2. Genome Biol 15: 550, 2014.

19. Mi H, Muruganujan A, Ebert D, Huang $X$ and Thomas PD PANTHER version 14: More genomes, a new PANTHER GO-slim and improvements in enrichment analysis tools. Nucleic Acids Res 47: D419-D426, 2019.

20. Kanehisa M and Goto S: KEGG: Kyoto encyclopedia of genes and genomes. Nucleic Acids Res 28: 27-30, 2000

21. Kanehisa M, Sato Y, Furumichi M, Morishima K and Tanabe M: New approach for understanding genome variations in KEGG. Nucleic Acids Res 47: D590-D595, 2019.

22. Latunde-Dada GO: Ferroptosis: Role of lipid peroxidation, iron and ferritinophagy. Biochim Biophys Acta Gen Subj 1861: 1893-1900, 2017.

23. Chen K, Liu H, Liu Z, Bloomer W, Amos CI, Lee JE, Li X, Nan $\mathrm{H}$ and Wei Q: Genetic variants in glutamine metabolic pathway genes predict cutaneous melanoma-specific survival. Mol Carcinog 2019 (Epub ahead of print).

24. Cheng M, Bhujwalla ZM and Glunde K: Targeting phospholipid metabolism in cancer. Front Oncol 6: 266, 2016.

25. Zou RC, Xiao SF, Shi ZT, Ke Y, Tang HR, Wu TG, Guo ZT, Ni F, Li WX and Wang L: Identification of metabolism-associated pathways and genes involved in male and female liver cancer patients. J Theor Biol 480: 218-228, 2019.

26. Ikhlas S and Ahmad M: Metformin: Insights into its anticancer potential with special reference to AMPK dependent and independent pathways. Life Sci 185: 53-62, 2017.

27. Tyszka-Czochara M, Bukowska-Strakova $\mathrm{K}$ and Majka $\mathrm{M}$ : Metformin and caffeic acid regulate metabolic reprogramming in human cervical carcinoma SiHa/HTB-35 cells and augment anticancer activity of Cisplatin via cell cycle regulation. Food Chem Toxicol 106: 260-272, 2017.

28. Wang T, Liu B, Guan Y, Gong M, Zhang W, Pan J, Liu Y, Liang R, Yuan Y and Ye L: Melatonin inhibits the proliferation of breast cancer cells induced by bisphenol A via targeting estrogen receptor-related pathways. Thorac Cancer 9: 368-375, 2018.

29. Vallance $P$ and Chan N: Endothelial function and nitric oxide: Clinical relevance. Heart 85: 342-350, 2001.

30. Chiueh C, Lee S, Andoh T and Murphy D: Induction of antioxidative and antiapoptotic thioredoxin supports neuroprotective hypothesis of estrogen. Endocrine 21: 27-31, 2003.

31. Ronchetti SA, Machiavelli LI, Quinteros FA, Duvilanski BH and Cabilla JP: Nitric oxide plays a key role in ovariectomy-induced apoptosis in anterior pituitary: Interplay between nitric oxide pathway and estrogen. PLoS One 11: e0162455, 2016.

32. Schmidt AJ, Krieg J and Vedder H: Differential effects of glucocorticoids and gonadal steroids on glutathione levels in neuronal and glial cell systems. J Neurosci Res 67: 544-550, 2002.

33. Schapira A and Lodi R: Assessment of in vitro and in vivo mitochondrial function in Friedreich's ataxia and Huntington's disease. Methods Mol Biol 277: 293-307, 2004.

34. Yang X, Xu MM, Wang J and Xie JX: Effect of estrogen on iron metabolism in mammals. Sheng Li Xue Bao 68: 637-643, 2016.

35. Chen B, Li GF, Shen Y, Huang XI and Xu YJ: Reducing iron accumulation: A potential approach for the prevention and treatment of postmenopausal osteoporosis. Exp Ther Med 10: 7-11, 2015.

36. Xie Q, Xi G, Keep RF and Hua Y: Effects of gender and estrogen receptors on iron-induced brain edema formation. Acta Neurochir Suppl 121: 341-345, 2016.

37. Asano M, Yamasaki K, Yamauchi T, Terui T and Aiba S Epidermal iron metabolism for iron salvage. J Dermatol Sci 87: 101-109, 2017.

38. El-Rifaie AA, Sabry D, Doss RW, Kamal MA and Abd El Hassib DM: Heme oxygenase and iron status in exosomes of psoriasis patients. Arch Dermatol Res 310: 651-656, 2018. 
39. Miniaci MC, Irace C, Capuozzo A, Piccolo M, Di Pascale A, Russo A, Lippiello P, Lepre F, Russo G and Santamaria R: Cysteine prevents the reduction in keratin synthesis induced by iron deficiency in human keratinocytes. J Cell Biochem 117 402-412, 2016.

40. Pelle E, Jian J, Zhang Q, Muizzuddin N, Yang Q, Dai J, Maes D, Pernodet N, Yarosh DB, Frenkel K and Huang X: Menopause increases the iron storage protein ferritin in skin. J Cosmet Sci 64: 175-179, 2013

41. Roberts and Szego CM: The influence of steroids on uterine respiration and glycolysis. J Biol Chem 201: 21-30, 1953.

42. Faulds MH, Zhao C, Dahlman-Wright K and Gustafsson JÅ: The diversity of sex steroid action: Regulation of metabolism by estrogen signaling. J Endocrinol 212: 3-12, 2012.

43. Chen X, Qian Y and Wu S: The Warburg effect: Evolving interpretations of an established concept. Free Radic Biol Med 79: 253-263, 2015.

44. Liberti MV and Locasale JW: The warburg effect: How does it benefit cancer cells? Trends Biochem Sci 41: 211-218, 2016.

45. Potter M, Newport E and Morten KJ: The warburg effect: 80 years on. Biochem Soc Trans 44: 1499-1505, 2016.

46. Jhingran A, Russell AH, Seiden MV, Duska LR, Goodman A, Lee SL, et al: 84-Cancers of the Cervix, Vulva, and Vagina. In: Niederhuber JE, Armitage JO, Kastan MB, Doroshow JH, Tepper JE, editors. Abeloff's Clinical Oncology (Sixth Edition). Philadelphia: Content Repository Only!; 2020. p. 1468-1507.e8.

47. Valle A, Català-Niell A, Colom B, García-Palmer FJ, Oliver J and Roca P: Sex-related differences in energy balance in response to caloric restriction. Am J Physiol Endocrinol Metab 289: E15-E22, 2005.

48. Demonacos CV, Karayanni N, Hatzoglou E, Tsiriyiotis C, Spandidos DA and Sekeris CE: Mitochondrial genes as sites of primary action of steroid hormones. Steroids 61: 226-232, 1996.

49. Chen JQ, Eshete M, Alworth WL and Yager JD: Binding of MCF-7 cell mitochondrial proteins and recombinant human estrogen receptors alpha and beta to human mitochondrial DNA estrogen response elements. J Cell Biochem 93: 358-373, 2004.

50. Zhai P, Eurell TE, Cooke PS, Lubahn DB and Gross DR: Myocardial ischemia-reperfusion injury in estrogen receptoralpha knockout and wild-type mice. Am J Physiol Heart Circ Physiol 278: H1640-H1647, 2000.

51. Zhai P, Eurell TE, Cotthaus R, Jeffery EH, Bahr JM and Gross DR: Effect of estrogen on global myocardial ischemiareperfusion injury in female rats. Am J Physiol Heart Circ Physiol 279: H2766-H2775, 2000.

52. Thompson CJ, Tam NN, Joyce JM, Leav I and Ho SM: Gene expression profiling of testosterone and estradiol-17 beta-induced prostatic dysplasia in Noble rats and response to the antiestrogen ICI 182,780. Endocrinology 143: 2093-2105, 2002.

53. Weisz A, Basile W, Scafoglio C, Altucci L, Bresciani F, Facchiano A, Sismondi P, Cicatiello L and De Bortoli M: Molecular identification of ERalpha-positive breast cancer cells by the expression profile of an intrinsic set of estrogen regulated genes. J Cell Physiol 200: 440-450, 2004

54. Wang J, Green PS and Simpkins JW: Estradiol protects against ATP depletion, mitochondrial membrane potential decline and the generation of reactive oxygen species induced by 3-nitroproprionic acid in SK-N-SH human neuroblastoma cells. J Neurochem 77: 804-811, 2001.

55. Nilsen J and Brinton RD: Mitochondria as therapeutic targets of estrogen action in the central nervous system. Curr Drug Targets CNS Neurol Disord 3: 297-313, 2004

56. Berg JM,Tymoczko JL, Gatto GJ and Stryer L: Biochemistry 2015.

57. Kim NH, Cha YH, Lee J, Lee SH, Yang JH, Yun JS, Cho ES, Zhang X, Nam M, Kim N, et al: Snail reprograms glucose metabolism by repressing phosphofructokinase PFKP allowing cancer cell survival under metabolic stress. Nat Commun 8: 14374, 2017.

58. Glunde K, Jie C and Bhujwalla ZM: Molecular causes of the aberrant choline phospholipid metabolism in breast cancer. Cancer Res 64: 4270-4276, 2004.
59. Palmisano BT, Zhu L and Stafford JM: Role of estrogens in the regulation of liver lipid metabolism. Adv Exp Med Biol 1043: 227-256, 2017.

60. Di Croce L, Vicent GP, Pecci A, Bruscalupi G, Trentalance A and Beato M: The promoter of the rat 3-hydroxy-3-methylglutaryl coenzyme A reductase gene contains a tissue-specific estrogen-responsive region. Mol Endocrinol 13: 1225-1236, 1999.

61. Wang D, Zhu W, Wang Y, Yan J, Teng M, Miao J and Zhou Z: Metabolomics approach to investigate estrogen receptor-dependent and independent effects of o, $\mathrm{p}^{\prime}$-DDT in the uterus and brain of immature mice. J Agric Food Chem 65: 3609-3616, 2017.

62. Marín-Hernández A, Gallardo-Pérez JC, Ralph SJ, Rodríguez-Enríquez S and Moreno-Sánchez R: HIF-1alpha modulates energy metabolism in cancer cells by inducing over-expression of specific glycolytic isoforms. Mini Rev Med Chem 9: 1084-1101, 2009.

63. Zhang X, Ma L, Qi J, Shan H, Yu W and Gu Y: MAPK/ERK signaling pathway-induced hyper-O-GlcNAcylation enhances cancer malignancy. Mol Cell Biochem 410: 101-110, 2015.

64. Han J, Zhang L, Guo H, Wysham WZ, Roque DR, Willson AK, Sheng X, Zhou C and Bae-Jump VL: Glucose promotes cell proliferation, glucose uptake and invasion in endometrial cancer cells via AMPK/mTOR/S6 and MAPK signaling. Gynecol Oncol 138: 668-675, 2015.

65. Cao M, Jiang J, Du Y and Yan P: Mitochondria-targeted antioxidant attenuates high glucose-induced P38 MAPK pathway activation in human neuroblastoma cells. Mol Med Rep 5: 929-934, 2012

66. Faubert B, Boily G, Izreig S, Griss T, Samborska B, Dong Z, Dupuy F, Chambers C, Fuerth BJ, Viollet B, et al: AMPK is a negative regulator of the Warburg effect and suppresses tumor growth in vivo. Cell Metab 17: 113-124, 2013

67. Lipovka Y, Chen H, Vagner J, Price TJ, Tsao TS and Konhilas JP: Oestrogen receptors interact with the $\alpha$-catalytic subunit of AMP-activated protein kinase. Biosci Rep 35: e00264, 2015.

68. Linher-Melville K, Zantinge S and Singh G: Liver kinase B1 expression (LKB1) is repressed by estrogen receptor alpha (ER $\alpha)$ in MCF-7 human breast cancer cells. Biochem Biophys Res Commun 417: 1063-1068, 2012

69. Artaza-Irigaray C, Molina-Pineda A, Aguilar-Lemarroy A, Ortiz-Lazareno P, Limón-Toledo LP, Pereira-Suárez AL, Rojo-Contreras W and Jave-Suárez LF: E6/E7 and E6* from HPV16 and HPV18 upregulate IL-6 expression independently of p53 in keratinocytes. Front Immunol 10: 1676, 2019.

70. Bridges HR, Sirviö VA, Agip AN and Hirst J: Molecular features of biguanides required for targeting of mitochondrial respiratory complex I and activation of AMP-kinase. BMC Biol 14: 65, 2016.

71. Brown KA, Hunger NI, Docanto M and Simpson ER: Metformin inhibits aromatase expression in human breast adipose stromal cells via stimulation of AMP-activated protein kinase. Breast Cancer Res Treat 123: 591-596, 2010.

72. Zhang J, Zhang B, Yin Z, Chen F, Liu T, Xu H, Liu Y and Zhou X: Effects of metformin on the estrogen-induced proliferation and the expression of ER in human endometrial cancer cells. Zhonghua Fu Chan Ke Za Zhi 49: 932-937, 2014 (In Chinese).

73. Kim J,Lee J, Jang SY, Kim C, Choi Y and Kim A: Anticancer effect of metformin on estrogen receptor-positive and tamoxifen-resistant breast cancer cell lines. Oncol Rep 35: 2553-2560, 2016.

74. Scherbakov AM, Sorokin DV, Tatarskiy VV Jr, Prokhorov NS, Semina SE, Berstein LM and Krasil'nikov MA: The phenomenon of acquired resistance to metformin in breast cancer cells: The interaction of growth pathways and estrogen receptor signaling. IUBMB Life 68: 281-292, 2016.

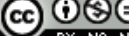

This work is licensed under a Creative Commons Attribution-NonCommercial-NoDerivatives 4.0 International (CC BY-NC-ND 4.0) License. 